\title{
Imaging spectrum of abnormal subcutaneous and visceral fat distribution
}

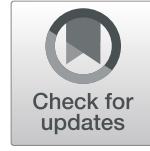

\author{
Asako Yamamoto ${ }^{1 *}$ (D) Yoshinao Kikuchi ${ }^{2}$, Toru Kusakabe ${ }^{3}$, Hideyuki Takano ${ }^{4}$, Keita Sakurai ${ }^{1}$, Shigeru Furui ${ }^{1}$ and \\ Hiroshi Oba ${ }^{1}$
}

\begin{abstract}
Adipose tissue plays multiple and complex roles not only in mechanical cushioning and energy storage but also as an important secretory organ that regulates energy balance and homeostasis multilaterally. Fat tissue is categorized into subcutaneous fat tissue (SCAT) or visceral fat tissue (VSA) depending on its distribution, with the two having different metabolic functions. Near-total lack of fat in congenital/acquired generalized lipodystrophy, cachexia, or any other severe malnutrition condition induces severe multi-organ dysfunction due to lack of production of leptin and other adipokines. Increased visceral fat tissue secondary to obesity, hypercortisolism, or multiple symmetric lipomatosis raises the risk of insulin resistance, cardiac complications, and airway or spinal canal stenosis, although the fat distribution pattern differs in each condition. Partial abnormal fat distribution conditions such as HIV/HAART therapy-associated lipodystrophy, familial partial lipodystrophies, and acquired partial lipodystrophy frequently show a mixture of lipoatrophy and lipohypertrophy with metabolic dysfunction. Characteristic imaging features in conditions with local abnormal fat distribution can provide information about a patient's co-existent/unrecognized disease(s), past medical history, or lifestyle. Knowledge of characteristic abnormal fat distribution patterns can contribute to proper and timely therapeutic decision-making and patient education.
\end{abstract}

Keywords: Fat, Lipodystrophy, Lipohypertrophy, Lipoatrophy, Bone marrow

\section{Key points}

- Adipose tissue plays multiple and complex roles not only in mechanical cushioning and energy storage, but also as a secretory organ that regulates homeostasis.

- It is essential to understand the anatomy and function of fat tissue to facilitate recognition of abnormal conditions and associated disorders.

- Generalized fat loss induces severe multi-organ dysfunction due to lack of production of leptin or other adipokines.

- Generalized or partial excessive fat accumulation can raise the risk of cardiac/respiratory/neurological disorders and insulin-resistance.

- Partial or localized conditions show characteristic distribution patterns on images, possibly shedding

\footnotetext{
* Correspondence: asakonemurinomori@yahoo.co.jp

'Department of Radiology, Teikyo University School of Medicine, 2-11-1 Kaga Itabashi-ku, Tokyo 173-8606, Japan

Full list of author information is available at the end of the article
}

light on the patient's co-existent/hidden disease, past medical history, or lifestyle.

\section{Background}

Until the middle of the twentieth century, adipose tissue was of little interest to scientists, because its sole function was considered to be tissue support [1]. It has now become clear, however, that adipose tissue plays multiple and complex roles not only in mechanical cushioning and energy storage but also as a secretory organ that helps to regulate energy balance, homeostasis, appetite, inflammation, insulin sensitivity, and lipid metabolism [2]. Fat tissue is categorized as subcutaneous fat tissue (SCAT) or visceral fat tissue (VSA) depending on its distribution, and white adipose tissue and brown adipose tissue on its function.

For abnormal fat distribution, terms such as lipodystrophy, lipohypertrophy, or lipoatrophy are used. Lipodystrophy is an umbrella term used to describe a diverse group of metabolic disorders characterized by either complete or partial loss of fat (lipoatrophy), which may occur in 
conjunction with pathological accumulation of fat in other distinct regions of the body. Conditions that can cause lipodystrophy are classified as genetic or acquired in etiology, but progressing genetic research may change our understanding of their etiology from acquired to genetic or genetic phenotyping in the near future.

There is considerable heterogeneity related to the pattern and extent of fat loss among conditions showing abnormal fat distribution. In this paper, we categorized these conditions into generalized and non-generalized (partial and localized) distribution patterns: those showing abnormal adipose distribution affecting nearly the entire body (generalized), those affecting multiple limbs (partial), and those showing small, discrete areas of involvement (localized). Conditions of generalized abnormal fat deposition including congenital and acquired generalized lipodystrophy exhibit excessive or inadequate fat accumulation not only in SCAT and VAT, but also in the bone marrow. These conditions derive life-threatening metabolic dysfunction. Partial conditions represented by HIV-1/highly active antiretroviral therapy (HAART)-associated lipodystrophy syndrome frequently show an uneven mixture of lipohypertrophy and lipoatrophy. The severity of this complication also varies, and it may be associated with conditions such as insulinresistance or airway/spinal canal stenosis. The localized pattern, such as that induced by trauma or mechanical stress-related conditions, frequently exhibits characteristic imaging features, which may provide information about a patient's co-existent disease(s) and lifestyle.

This paper focuses on the abnormal distribution of subcutaneous and visceral adipose tissue, divided into generalized and non-generalized patterns (Table 1). Syndromes associated with vascular malformations can also present as lipohypertrophy but are not discussed here.

\section{Normal adipose tissue anatomy, types, and physiology \\ Anatomy}

Mature adipocytes contain only one-third of adipose tissue. Nerves and vessels, fibroblasts and adipocyte precursor cells contain the remaining two-thirds of adipose tissue [3]. Mature adipocytes are divided into two cytotypes, white and brown, recognized by their colors and functions. White adipocytes are unilocular large spherical droplets [4]. On the other hand, brown adipocytes are multilocular with abundant mitochondria packed with cristae within the cytoplasm.

\section{White adipose tissue (WAT) and brown adipose tissue (BAT)}

It is well known that mammals have two types of adipose tissue: white adipose tissue (WAT), mainly composed of white adipocytes, and brown adipose tissue
(BAT), mainly composed of brown adipocytes [2]. They are mixed to various degrees depending on factors such as the individual's age and circumstances (e.g., starvation and cold exposure). White adipose tissue (WAT) comprises most of adult fat. Although WAT and BAT both receive a vascular and nerve supply, BAT contains a richer vascular tree, dense with numerous capillaries [2].

The physiology of WAT can be summarized into three overlapping categories: lipid metabolism, glucose metabolism, and endocrine function [3]. Leptin, one of the most thoroughly investigated adipokines, is referred to in the next section in congenital generalized lipodystrophy.

In neonates, BAT can be found in several areas including the interscapular region, axillae, and muscles in the neck [5-7]. In adults, no discrete collection of BAT is observed. The function of BAT in adult humans has been investigated but not determined to date.

\section{Subcutaneous and visceral fat tissue}

There are two major anatomic distributions with unique anatomic, metabolic, or endocrine properties: visceral (VAT) and subcutaneous adipose tissue (SCAT). VAT is divided into intraperitoneal and retroperitoneal distribution. SCAT occupies about $80 \%$ of all body fat in healthy adults [8]. SCAT is further divided into superficial subcutaneous and deep subcutaneous adipose tissue [9].

The metabolic function of VAT and SCAT is substantially different. For example, visceral adipocytes are more metabolically active and have a greater lipolytic activity compared with SCAT. Adipocytes from VAT are more insulin-resistant than adipocytes from SCAT $[10,11]$. SCAT is the major source of leptin production [8]. Superfluous energy accumulates in adipocytes at SCAT, which acts as a metabolic sink. Only when the capacity of SCAT is exceeded or impaired does VAT accumulation occurs.

\section{Generalized abnormal fat distribution Congenital generalized lipodystrophy (Berardinelli-Seip syndrome) (CGL)}

Congenital (genetic) lipodystrophy has been reported in about 1000 patients with various types related to the pattern of fat loss and genetic molecular defect $[12,13]$. Congenital generalized lipodystrophy is an autosomal recessive trait, with an incidence estimated at less than one in 12 million [13]. They are recognized at birth by a near-total lack of body fat and increased muscular appearance. Markedly low serum levels of leptin and adiponectin secreted from adipose tissue drive insulin resistance and its complications such as diabetes mellitus, dyslipidemia, hepatic steatosis, acanthosis nigricans, polycystic ovarian disease, and hypertension [12]. 
Table 1 Conditions showing abnormal subcutaneous and visceral fat distribution

\begin{tabular}{llll}
\hline & Subcutaneous & Visceral \\
\hline Generalized & & $\downarrow$ \\
Congenital generalized lipodystrophy loss \\
Acquired generalized lipodystrophy & $\downarrow$ & $\downarrow$ & $\downarrow$ \\
Cachexia & $\downarrow$ & $\downarrow$ & \\
Malnutrition & $\downarrow$ & $\uparrow$ \\
Hypercortisolism & $\downarrow$ & $\uparrow$ \\
Obesity & $\uparrow$ & \\
Non-generalized & & $\rightarrow \sim \uparrow$ \\
Multiple symmetric lipomatosis & $\uparrow$ & $\rightarrow \sim \uparrow$ \\
HIV/HAART therapy-associated & $\uparrow \sim \downarrow$ & $\rightarrow$ \\
Drug injection-associated & $\uparrow(\sim \downarrow)$ & $\rightarrow$ \\
Trauma and stress-associated & $\uparrow \sim \downarrow$ & $\rightarrow \sim \uparrow$ \\
Familial partial lipodystrophies & $\uparrow \sim \downarrow$ & $\rightarrow$ \\
Autoimmune disease-associated & $\downarrow$ & $\rightarrow \sim \uparrow$ \\
Acquired partial lipodystrophy & $\downarrow$ & \\
\hline
\end{tabular}

Bold conditions are shown in figures

$B M$ bone marrow

$\mathrm{CT}$ and MRI demonstrate the nearly complete absence of adipose tissue well, whereas adipose tissue may be preserved in the orbits, mouth, tongue, palms and soles, scalp, perineum, and periarticular regions [14] (Figs. 1 and 2). Lytic lesions may be formed in the long bones or appendicular bones after puberty [15]. Disappearance of adipose tissue from bone marrow should be anticipated on MRI, which may make any bone lesion difficult to detect. The imaging differential diagnoses are Werner syndrome, anorexia nervosa, cachexia, and other severe wasting conditions. The finding of normal or hypertrophic muscles and past history including medication history are key points for making the diagnosis. Acquired generalized lipodystrophy may show almost the same clinical and imaging findings although the onset is usually during childhood and the distribution and extent of fat loss are variable. Genes for congenital lipodystrophies including CGL continue to be reported [12]. Although there are many types of inherited partial lipodystrophy, most of them are extremely rare. Familial partial dystrophy and acquired partial lipodystrophy are mentioned briefly in the chapter of uneven lipodystrophy.

\section{Acquired generalized lipodystrophy (AGL)/Lawrence syndrome}

AGL is a very rare acquired form of generalized lipodystrophy that develops in a previously healthy child or adult. Loss of SCAT occurs usually during childhood in patients with AGL showing a variable pattern and extent [12]. Although most patients show generalized loss of fat, some also show spared areas such as VAT and bone marrow fat. Severe hepatic steatosis, fibrosis, and diabetes mellitus are the major complication in AGL. The pathogenesis of fat loss in patients with AGL remains unknown, but previous infection can be linked to this syndrome because histologic analysis of subcutaneous tissue reveals panniculitis [16]. Antibodies against adipocyte-membrane antigens have been detected in a few cases. AGL may coexist with autoimmune diseases such as Hashimoto's thyroiditis, rheumatoid arthritis, hemolytic anemia, and chronic active hepatitis [2].

\section{Cachexia}

Cachexia is clinically defined as $>5 \%$ weight loss over 3 months or $>10 \%$ within the previous 6 months in patients with malignancy [17]. Fat loss is a poor prognostic factor in advanced cancer regardless of a patient's body weight [18]. Adipose tissue metabolism and whole-body fat mass are regulated through two major pathways: lipolysis (fat breakdown) and lipogenesis (fat synthesis). Adipose atrophy in cancer patients is attributed to increased lipolysis and fat oxidation, decreased lipogenesis, impaired lipid deposition and adipogenesis, and browning of white adipose tissue [17]. Cancer patients exhibit smaller adipocytes compared with non-cancer ones, but the total fat cell number is not altered [19]. Fat loss occurs more rapidly and precociously than the reduction of lean mass in cachexia, with extension in rush especially in the immediate period preceding death [20]. CT shows not only fat depletion but also increased density of visceral and subcutaneous fat that may reflect depletion of fat cell size with fibrotic, inflammatory, or edematous change (Fig. 3). 


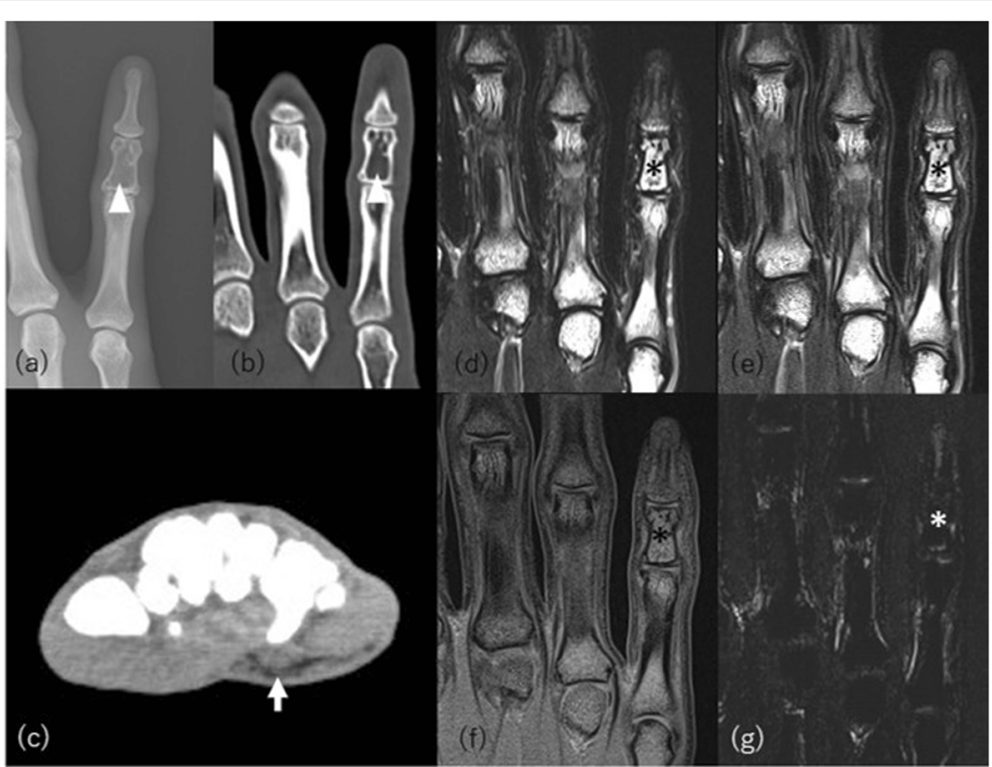

Fig. 1 A 23-year-old woman with congenital generalized lipodystrophy and fifth finger pain. Lytic lesion (arrowheads) was evident on (a) radiograph and (b) CT in the fifth middle phalange. c CT showed almost complete loss of fat tissue other than the palmar fat pad (arrow). MRI showed complete lack of bone marrow adipose tissue. Coronal (d) T2-weighted and (e) STIR images show almost the same signal. f T1-weighted image shows no adipose high signal intensity. An asterisk denotes the referred lytic lesion. $\mathbf{g}$ DIXON-based fat image shows almost complete loss of fat high signal in the bone marrow and soft tissue

\section{Eating disorder}

Eating disorders are characterized by a persistent disturbance of eating that impairs health or psychosocial functioning with the highest mortality of any psychiatric disorder [21]. Anorexia nervosa and bulimia nervosa are serious life-threatening eating disorders. Anorexia nervosa is characterized by self-starvation and excessive weight loss. Bulimia nervosa is characterized by a cycle of binging and compensatory behaviors such as selfinduced vomiting designed to undo or compensate for the effects of binge eating.
Patients with severe anorexia or bulimia nervosa can show extremely depleted body fat mass with increased attenuation on CT [22]. Visceral adipose tissue attenuation can be a biomarker of current and prior disease status [22]. Not only subcutaneous and visceral fat, but also diminishment of the normal hyperintense T1weighted signal is observed from bone marrow (Fig. 4). The signal alteration of bone marrow is named as serous atrophy of bone marrow radiologically or gelatinous bone marrow pathologically. A variety of conditions such as chronic infection, malabsorption,

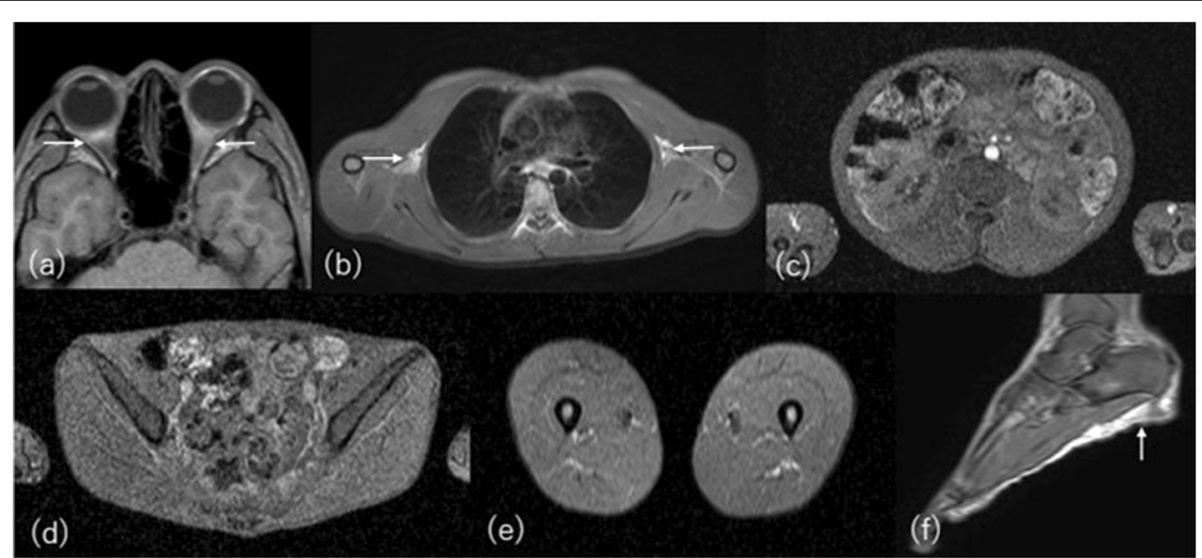

Fig. 2 Whole body MRI taken from the same CGL patient 10 years earlier. T1-weighted axial images at the level of (a) orbita, (b) axilla, (c) renal sinus, (d) pelvis, (e) thigh, and (f) sagittal image of foot show nearly complete absence of adipose tissue, which is however slightly preserved in the orbits, axillae, and soles (arrows) 


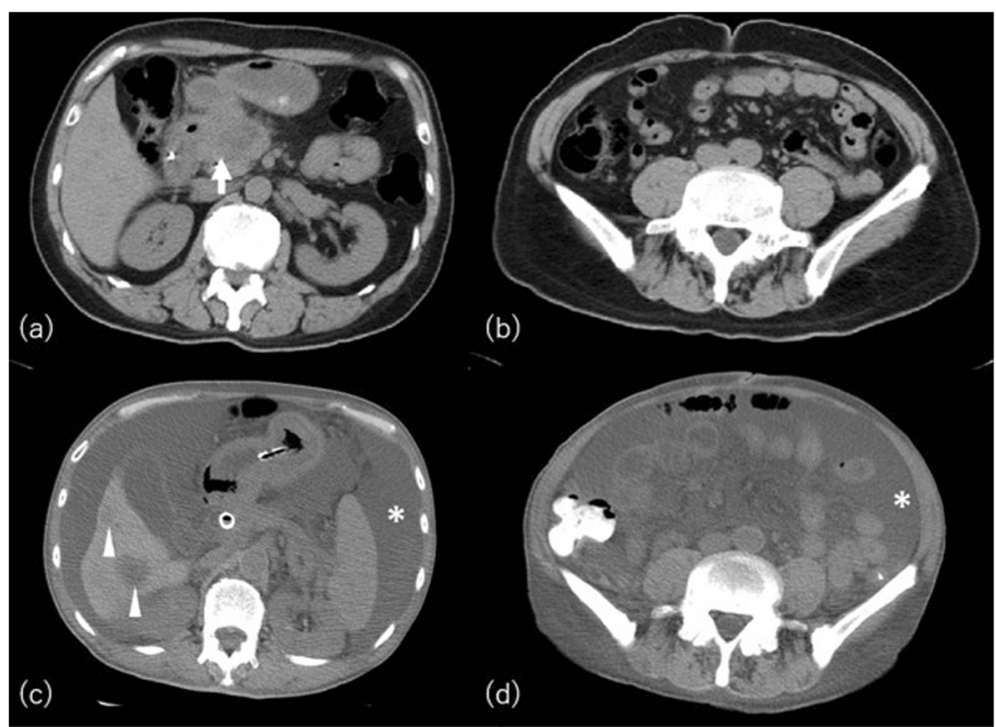

Fig. 3 A 68-year-old man with pancreatic cancer. Initial CT in our hospital (a, b) shows massive low-density mass in the head of the pancreas (arrow). CT performed 14 months later ( 2 months before death) (c, d) shows depletion and increased attenuation of subcutaneous and visceral adipose tissue. Hepatic metastases (arrowheads) and copious ascites (asterisks) are also observed

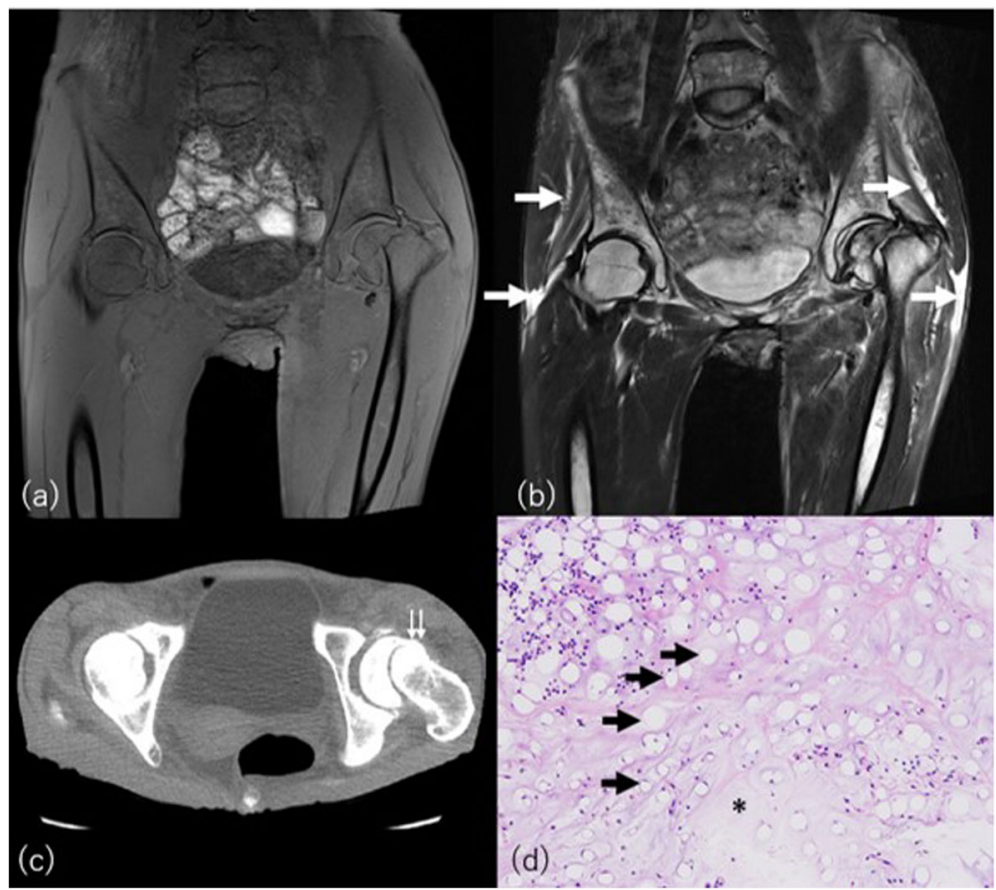

Fig. 4 A 48-year-old woman with serous atrophy of bone marrow from bulimia nervosa. a Coronal T1-weighted image demonstrates abnormal diffuse hypointense marrow signal with fracture of left femoral neck. b Coronal STIR demonstrates abnormal hyperintense signal in the bone marrow and surrounding subcutaneous or intermuscular tissue (arrows). c CT at the level of the femoral fracture (double arrow) shows depleted high attenuated fat tissue. $\mathbf{d}$ Histopathologically shrinkage of fat cells (black arrows), decrease of hematopoietic cells, and deposition of abundant amorphous extracellular gelatinous substances (asterisk) were observed (hematoxylin-eosin stain, $\times 100$ ) 


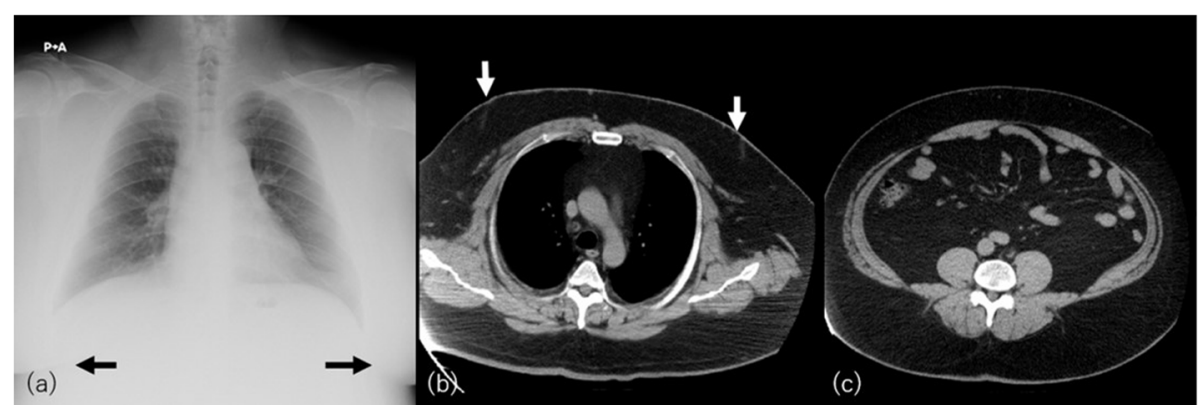

Fig. 5 A 37-year-old man with binge eating disorder and overeating habitus (BMI = 53.2). a Chest radiograph shows bilateral pseudogynecomastia (black arrows). b CT of the chest and (c) abdomen shows increase of subcutaneous and visceral adipose tissue. Note the absence of extensive growth of mammary gland but pure fat deposition on the breast (white arrows)

chronic heart and kidney failure, and alcoholism have been identified as causes of serous atrophy of bone marrow [23]. Skeletal growth retardation, in particular in young male patients, may also be evident on imaging studies. Osteoporosis occurs in up to $50 \%$ of patients with anorexia with seven times higher the risk of insufficient fracture in patients who have had anorexia for longer than 5 years than in healthy women of the same age [24].

Although obesity (BMI > 30) is not a single but multifactorial condition, binge eating disorder or overeating is one of the most important backgrounds. The increase of fat amount is characterized by increased adipocyte size. Subcutaneous and visceral fat amount is strongly associated with insulin resistance [25]. In obese patients, mass-like subcutaneous fat accumulation can be observed: pseudogynecomastia on the anterior chest wall and buffalo's hump on the posterior neck. In pseudogynecomastia, the underlying mass is not breast tissue but pure fat (Fig. 5). Buffalo hump can also occur in the course of HIV/HAART therapy, Cushing's syndrome, or long-time steroid use. Obesity and such conditions may overlap.

\section{Non-generalized (partial/localized) abnormal fat distribution}

A mixture of fat accumulation and lipoatrophy can occur in patients with this category.

\section{HIV-1/highly active antiretroviral therapy (HAART)- associated lipodystrophy syndrome (HALS)}

With the introduction of effective antiretroviral therapy, HALS has become one of its most important long-term adverse effects [26]. HALS includes subcutaneous fat loss (lipoatrophy), fat accumulation (lipohypertrophy), or a combination of both (Fig. 6). These morphologic abnormalities can also be associated with disorders of glucose and lipid metabolism.

Lipoatrophy manifests as a loss of fat mainly in the face, limbs, and buttocks [27]. Facial lipoatrophy is characterized by loss of the buccal and/or temporal fat pads, resulting in concave cheeks, prominent nasolabial folds, and
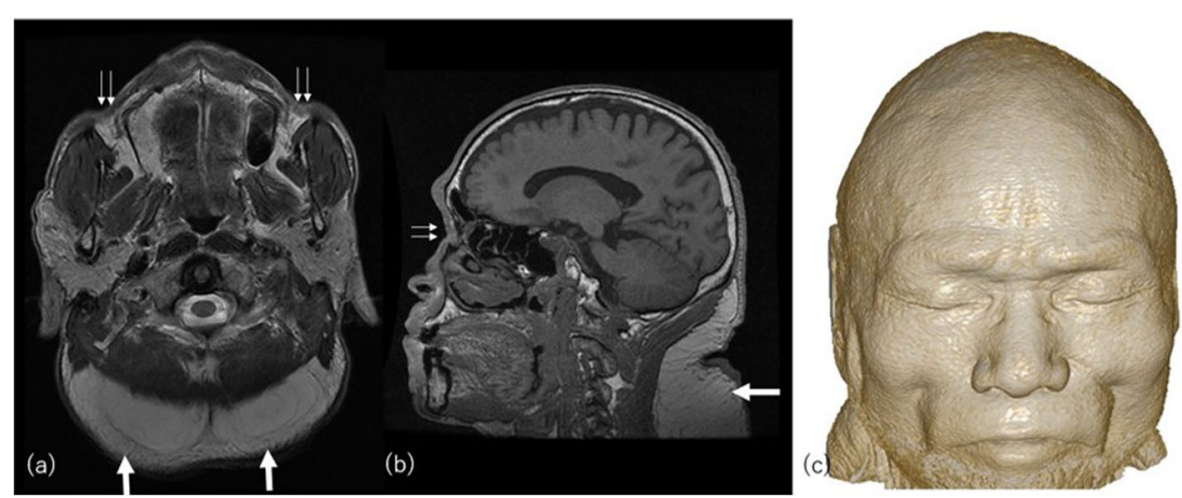

Fig. 6 A 47-year-old man with HALS. a Axial T2-weighted and (b) sagittal T1-weighted images show subcutaneous lipohypertrophy on the posterior neck (arrows). Marked loss of subcutaneous fat including buccal fat pad is shown in the face (arrowheads). c Volume-rendered threedimensional reformation image shows apparent concave cheeks and periorbital hollowing 


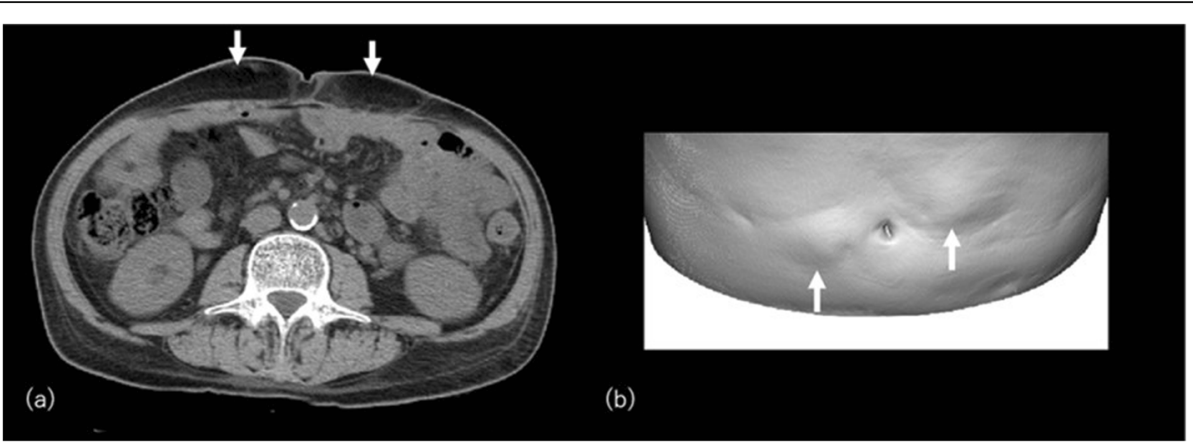

Fig. 7 A 66-year-old man with type I diabetes and insulin injection lipohypertrophy. a CT image at the level of belly button shows bilateral localized subcutaneous fat deposition on the anterior abdominal wall (arrows). b Volume-rendered three-dimensional reformation image show bilateral bulging of abdominal wall reflecting the insulin lipohypertrophy

periorbital hollowing [28]. It has been reported that an important fat loss has to exceed $30 \%$ to become evident clinically. The main risk factor for lipoatrophy is exposure to thymidine analog nucleoside reverse transcriptase inhibitors (NRTIs), which today, however, are no longer the first-line drugs resorted to [27].

Fat accumulation occurs in the trunk, cervical-dorsal area ("buffalo hump"), breasts, upper chest, or visceral adipose tissue. Dyslipidemia and insulin resistance frequently coexist in this condition. Risk factors for the development of fat deposition include increasing age, female sex, elevated baseline triglycerides, and higher body fat percentage [29].

\section{Insulin injection}

Abnormal reaction of subcutaneous fat to insulin injection is well known as lipohypertrophy and lipoatrophy.

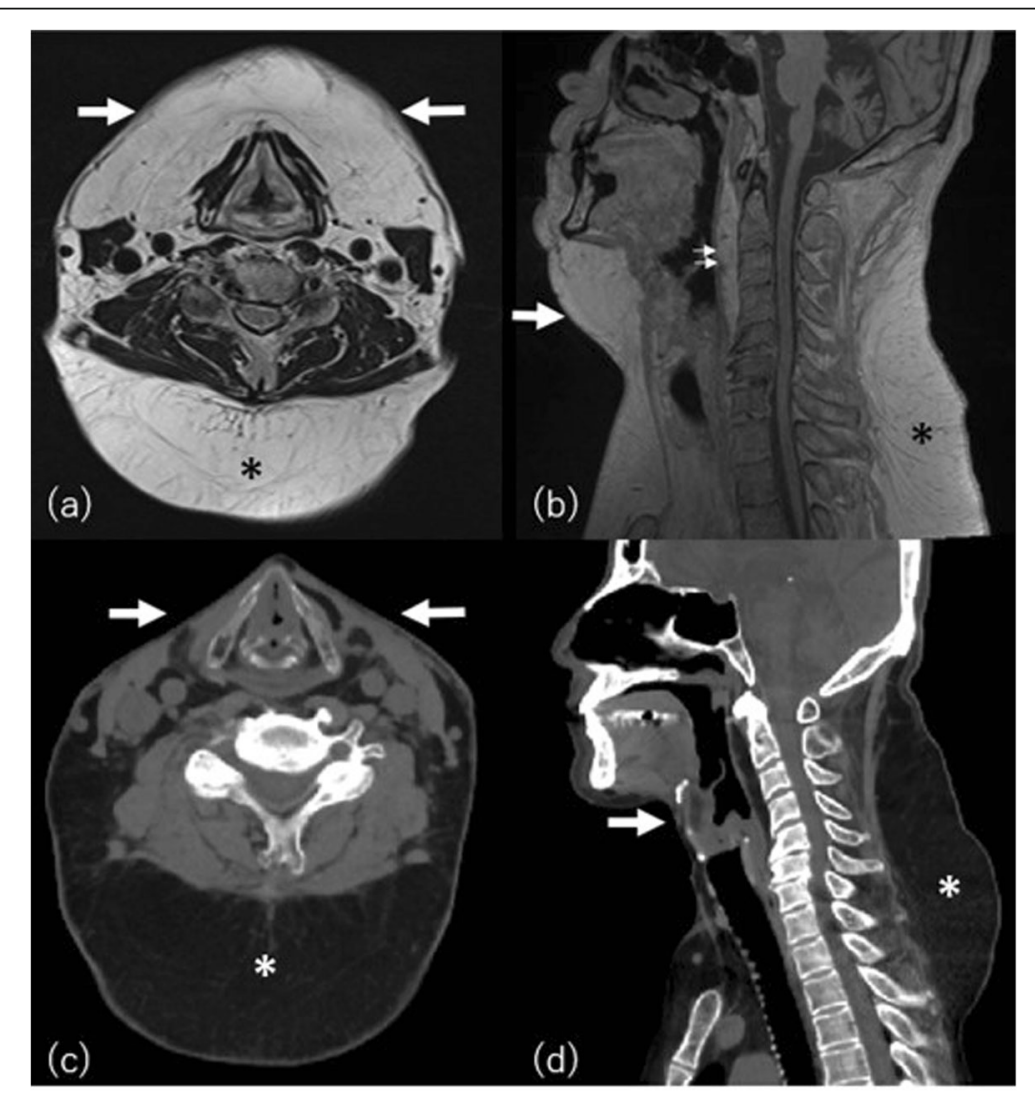

Fig. 8 A 45-year-old man with multiple symmetrical lipomatosis with sleep apnea. a Axial T2-weighted and (b) T1-weighted image show abnormal subcutaneous fat deposition in the anterior (arrows) and posterior neck (asterisks). Note the increase of adipose tissue also observed in the posterior pharyngeal space (small arrows). c Post liposuction axial and (d) sagittal reconstructed CT 2 years later. Subcutaneous fat volume in the anterior neck is markedly decreased (arrows), whereas in contrast, the fat deposition in the posterior neck has worsened (asterisk) 

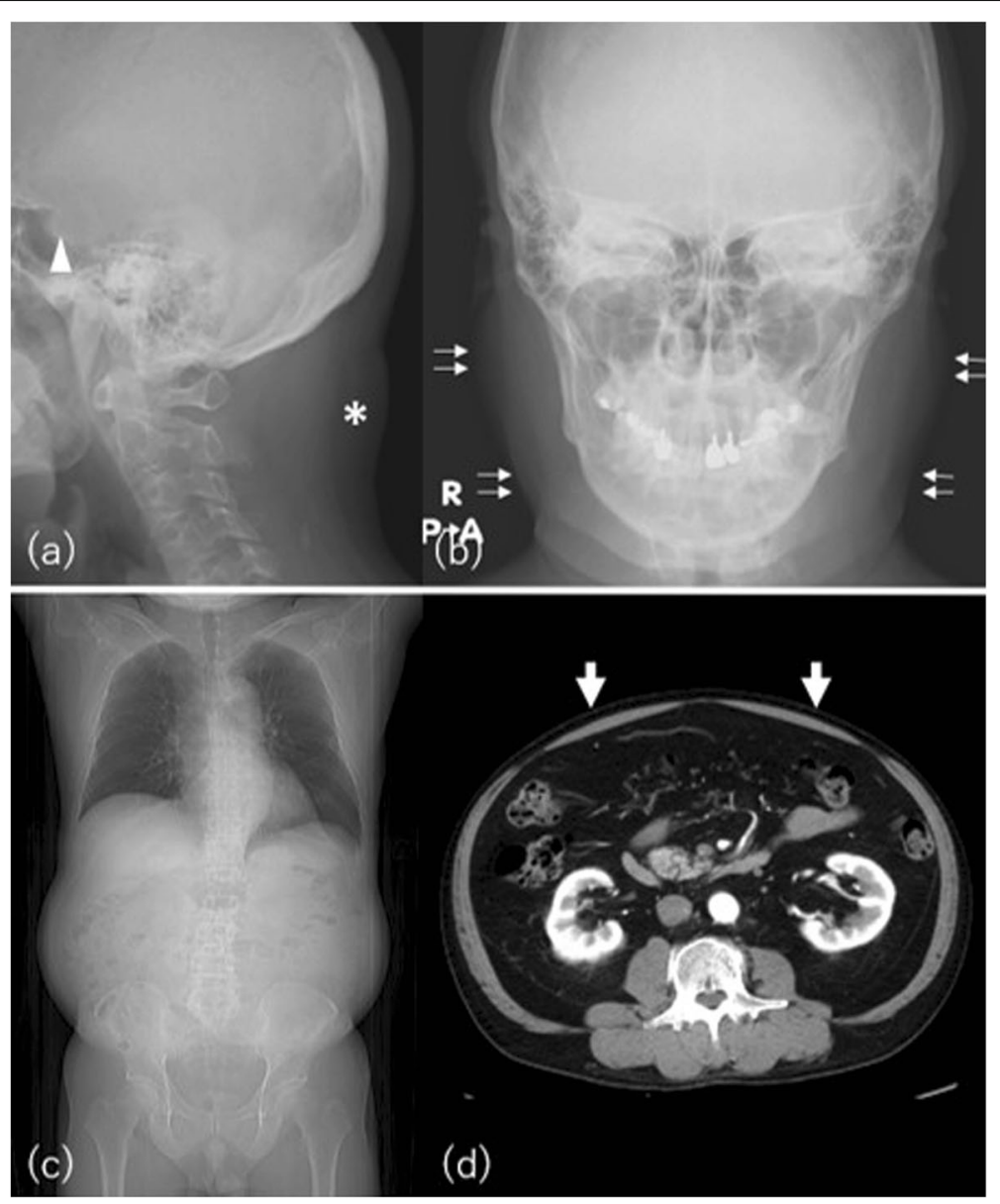

Fig. 9 A 52-year-old man with Cushing disease. a Lateral skull radiography shows "buffalo hump" on the posterior neck (asterisk). Note the enlarged sella due to pituitary macroadenoma (arrowhead). b Frontal skull radiograph shows a rounded shape of the face, "moon face" (double arrows). c CT scanogram shows characteristic central obesity. $\mathbf{d}$ CT image at the level of bilateral renal hilum shows marked visceral fat deposition, in contrast to subcutaneous fat thinning (boxed arrows)

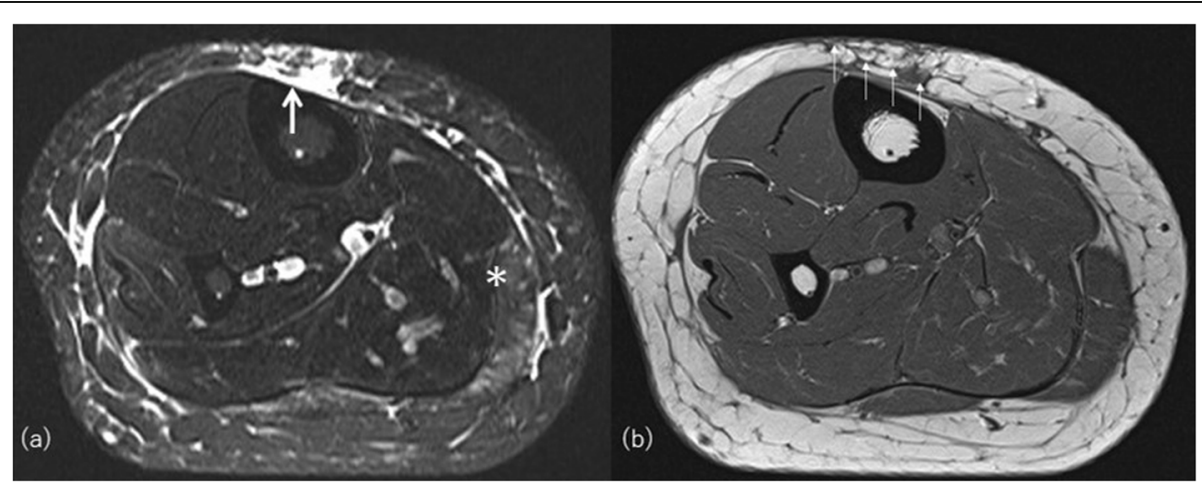

Fig. 10 A 48-year-old woman with deep morphea on her right thigh. a Axial fat saturated T2-weighted image shows hypersignal intensity in full thickness of subcutaneous fat on the anterior aspect (arrow). Increased signal intensity in gastrocnemius muscle (asterisks), muscle fasciae, and diffuse subcutaneous septal thickening are also demonstrated. b T1-weighted image clearly shows thinning of subcutaneous fat with cord-like low signal intensity (small arrows) 


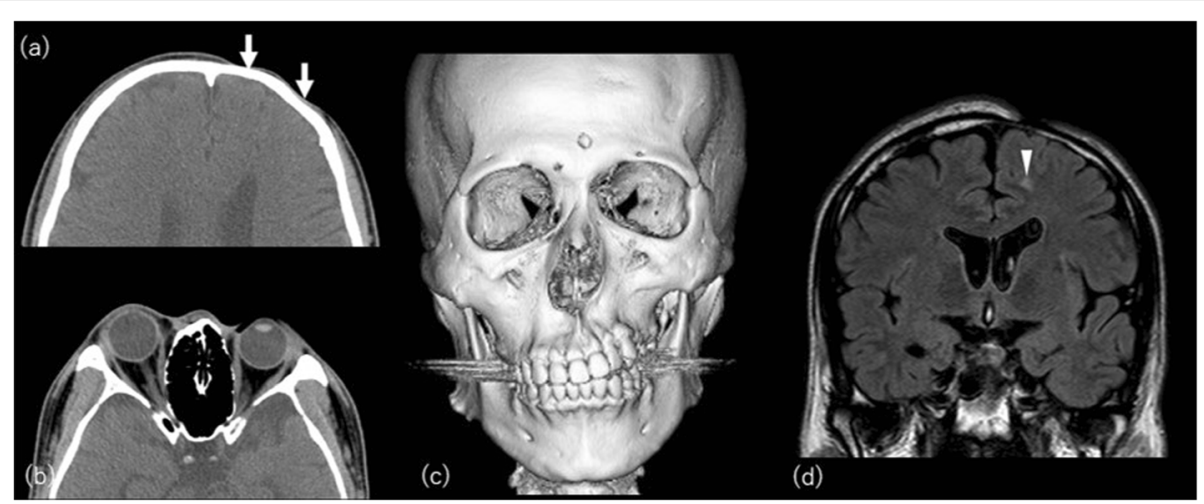

Fig. 11 A 29-year-old man with Parry-Romberg syndrome. a Axial CT images show asymmetrically decreased subcutaneous fat on the left side (arrows). $\mathbf{b}$ Hypoplasty of the left orbit is also evident. c Volume-rendered three-dimensional reformation image of facial bones highlights bony asymmetry of the face. There is a perceivable asymmetry of the maxillary bone as well. $\mathbf{d}$ Coronal FLAIR image shows subcortical high signal intensity area (arrowhead)

Insulin lipohypertrophy shows a tumor-like swelling of fatty tissue at the injection site due to the lipogenic effect of insulin (Fig. 7). Growth hormone receptor antagonist is also reported to be a cause of lipohypertrophy at the injection site [30]. Lipoatrophy, which is considered to be an immune complex-mediated inflammatory lesion, rarely occurs today since the advent of recombinant human insulin and insulin analogs
[31]. Lipohypertrophy remains a frequent complication of insulin therapy, reportedly in $28.7 \%$ of those with type 1 diabetes and 3.6\% with type 2 diabetes with a greater tendency of developing the lesion in patients using medium or long-acting insulin [32, 33]. Injection into lipohypertrophied sites may contribute to poor glycemic control due to an erratic absorption of the drug.

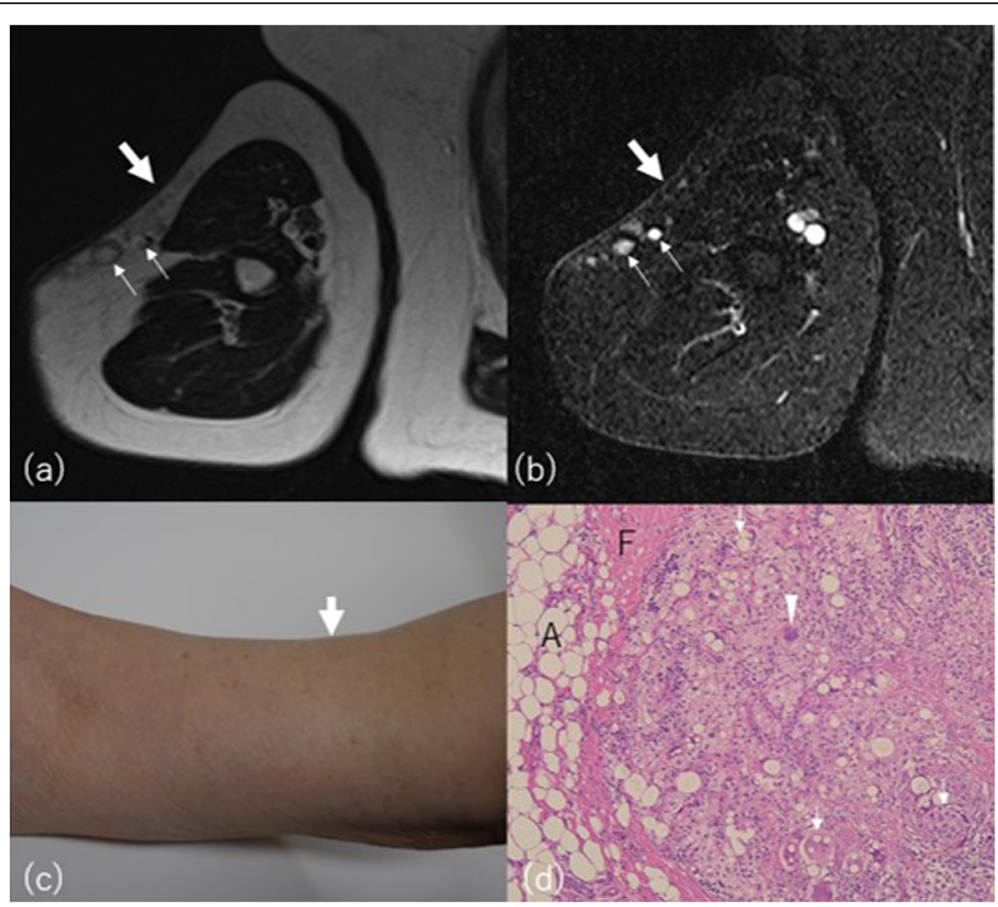

Fig. 12 A 59-year-old woman with post blunt trauma lipoatrophy on the right upper arm. a Axial T2-weighted and (b) STIR images show thinning of subcutaneous fat on the lateral aspects (arrows) with multiple high signal nodules (small arrows) showing small peripheral fat signal areas. c Photograph shows thinning of the lateral aspect of the upper arm with small hump (arrow). d Histologically fat necrosis with lipogranuloma was proven. Variably sized lipid vacuoles are surrounded by foam cells, foreign body-type (arrows), and Touton giant cells (arrowhead) in the resected lipogranuloma. A adipocytes, $F$ fibrosis (hematoxylin-eosin stain, $\times 100$ ) 


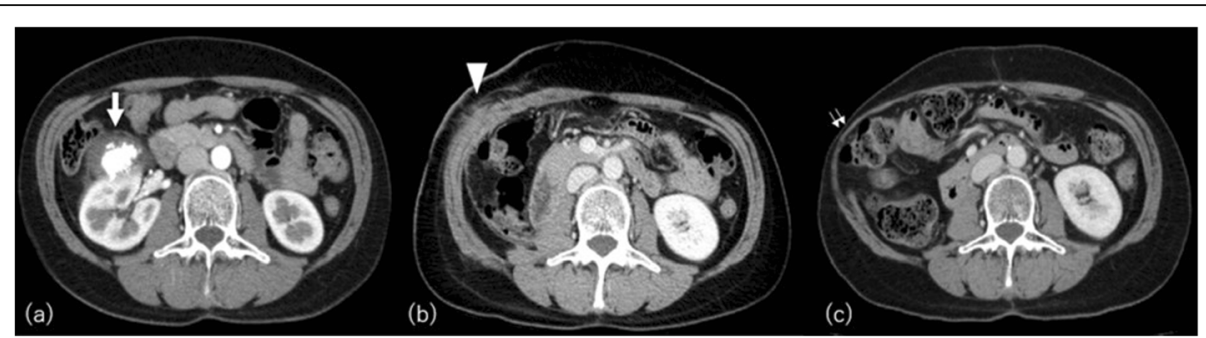

Fig. 13 A 59-year-old woman with post-surgery lipoatrophy. a CT image before operation shows calcified soft tissue density mass anterior to the right kidney (arrow). Right nephrectomy was done, and the lesion was pathologically diagnosed as dedifferentiated liposarcoma. b CT image one month after surgery shows fluffy opacity in the subcutaneous fat around the operated area (arrowhead) with abdominal wall muscle swelling. $\mathbf{c}$ CT image after 8 years shows local lipoatrophy (double arrow) with muscle atrophy

Multiple symmetric lipomatosis (Madelung's disease) (MSL) Madelung's disease, also known as benign symmetric lipomatosis, is a rare condition that shows a symmetrical accumulation of adipose tissue, primarily around the neck, back, shoulders, and upper trunk (Fig. 8). It usually affects adult males, mostly in the Mediterranean and eastern European population aged from 40 to 50 years [34]. MSL has a strong association with heavy alcohol intake. Alcohol cessation and weight control are recommended although they do not reverse or stop the course of the disease [35]. MSL is also found in non-alcoholics in association with mitochondrial DNA mutations [36]. A defect of adrenergic stimulated lipolysis or mitochondrial disorder of brown fat tissue has been considered as the etiology of this disease in recent studies [37].

Suprascapular and supraclavicular involvement is common and tracheal or esophageal compression due to deep space-occupying lesions is a life-threatening complication [38]. CT is the optimal modality to evaluate deep-seated fat accumulation. Palliative removal of fatty tissue by surgical resection or liposuction and by injection lipolysis is recommended when symptomatic.

\section{Cushing's syndrome/hypercortisolism}

Cushing's syndrome results directly from chronic exposure to excess glucocorticoid. It includes iatrogenic, ectopic adrenocorticotropic hormone (ACTH) syndrome, Cushing disease (pituitary ACTH-dependent Cushing's syndrome), and adrenal tumors [39]. The most common feature of patients with Cushing's syndrome is progressive central obesity (Fig. 9). Adipocytes from VAT are more insulin-resistant compared with SCAT. The amount of visceral fat is a striking factor underlying the enhanced cardiovascular risk seen in this condition and is mediated by insulin resistance [40, 41]. Central obesity can also induce hypertension through increased activity of adipose tissue renin-angiotensin-aldosterone system, sympathetic activation, and other mechanisms connected with insulin resistance.

The extremities are usually spared and may be wasted. Fat can also accumulate in the supraclavicular fossa, spinal canal (spinal epidural lipomatosis), cheeks (moon face), or dorsocervical fat pad (buffalo hump) [39, 42]. Buffalo hump in Cushing's syndrome is usually consistent with the general degree of obesity. In the muscle, weakness and proximal muscle wasting are induced by the catabolic effects of excess glucocorticoid on the

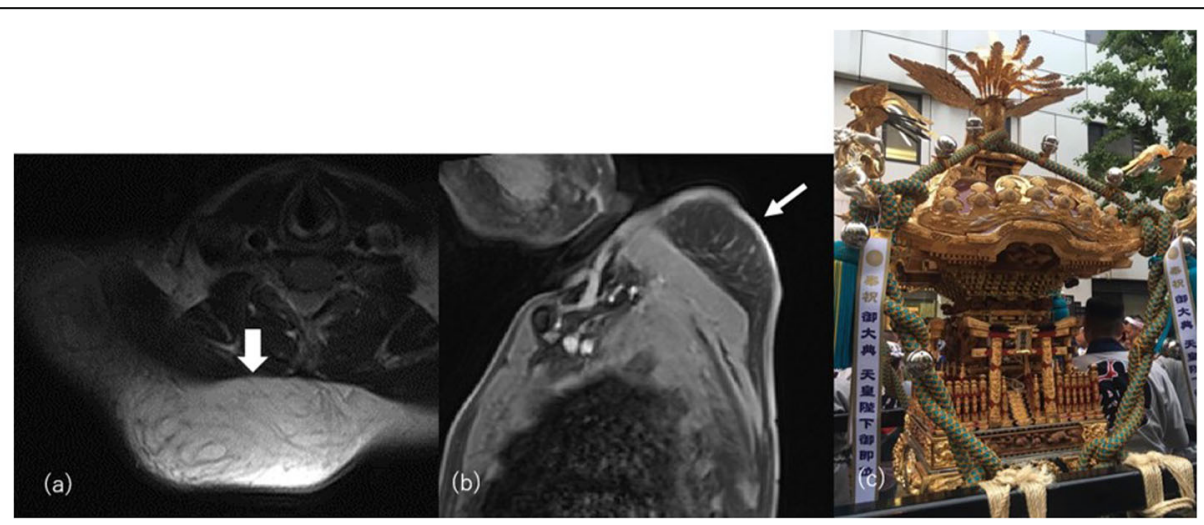

Fig. 14 A 60-year-old man with post-traumatic pseudolipoma on the right posterior neck. He had a history of carrying a mikoshi (Japanese portable shrine) daily. a Axial T1-weighted and $\mathbf{b}$ sagittal post-contrast fat-sat T1-weighted images show non-capsulated subcutaneous fat tissue proliferation on the right posterior neck (arrows). c Photograph of a mikoshi 


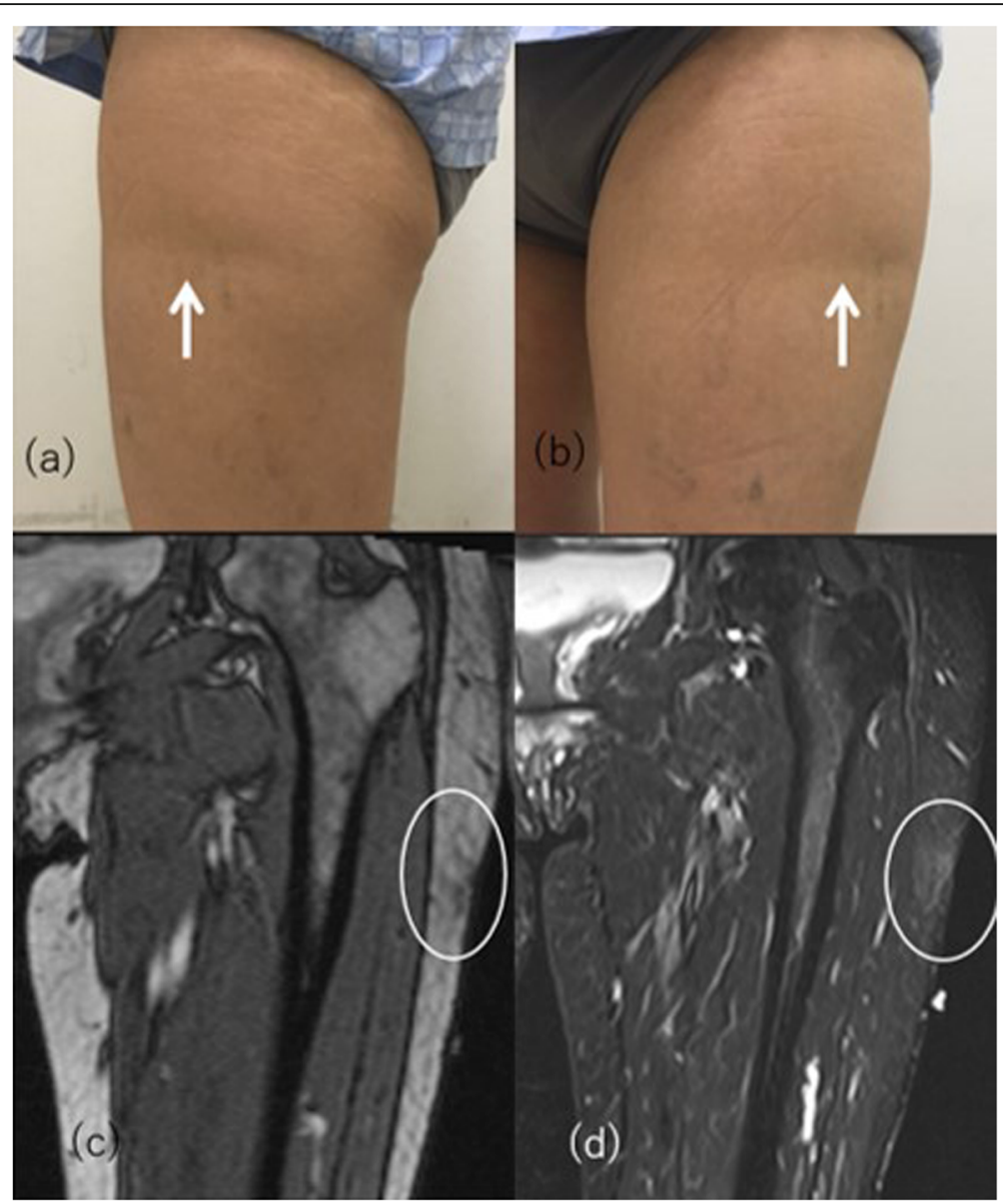

Fig. 15 A 47-year-old woman with semicircular lipoatrophy. a, b Linear horizontal depression on the lateral aspect of left thigh at $72 \mathrm{~cm}$ above the ground (arrows). She had a history of working leaning against the edge of her desk daily. $\mathbf{c}$, $\mathbf{d}$ Coronal localizer image and STIR show loss of localized subcutaneous fat tissue with slight edematous change (circle)

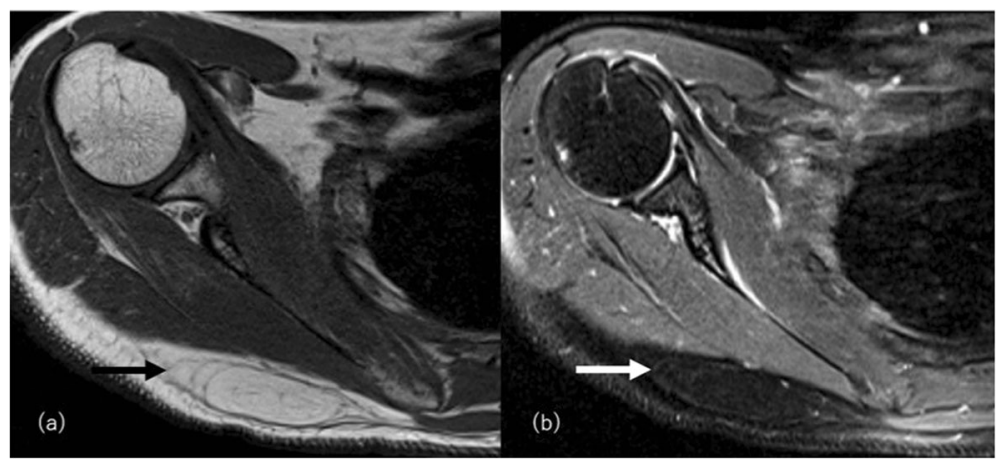

Fig. 16 Superficial lipoma in a 60-year-old woman on the right shoulder. a T1-weighted image and (b) fat-suppressed T2-weighted show a homogeneous fatty mass (arrows) with a similar signal intensity to that of the adjacent subcutaneous fat but with a thin capsule and thin internal septa 


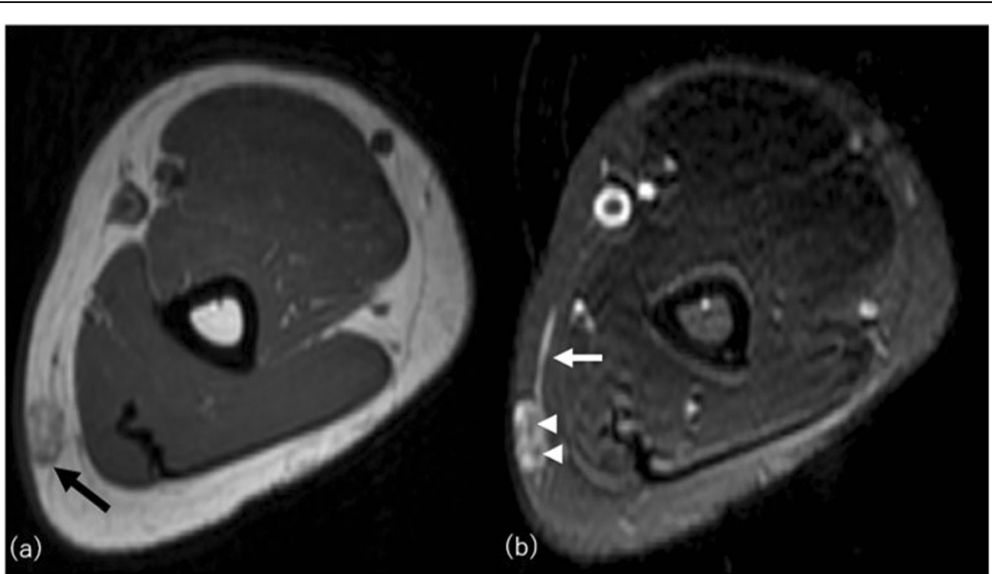

Fig. 17 Angiolipoma in a 29-year-old man on the left upper arm. a T1-weighted image shows a subcutaneous tiny mass with inhomogeneous high to intermediate signal intensity (arrow). b Fat-saturated T2-weighted image shows hyperintense signal with focal fat suppression (arrowhead) in the mass with connection to dilated subcutaneous vein (small arrow)

skeletal muscle. Osteoporosis is caused by decreased intestinal and renal calcium absorption and increased bone resorption [43].

\section{Autoimmune disease}

Localized scleroderma (morphea) and lupus erythematosus panniculitis (lupus erythematosus profundus (LEP)) are well-known connective tissue disorders involving the subcutaneous compartment resulting in lipoatrophy [44]. They are usually localized but rarely progress to acquired generalized lipoatrophy [12]. Morphea is classically confined to the skin and/or underlying tissues but may extend over muscular fascia, muscle tissue, tendons, joint synovia, and even bone marrow (deep morphea) (Fig. 10). Morphea usually manifests as a single wellcircumscribed lesion on the extremities or upper trunk, near the spine with keloid-like hard and shiny skin changes [45]. MRI shows localized lipoatrophy under the depressed thickened skin with or without varying degree of signal change in underlying fascia and musculature involvement. It is usually asymptomatic and not associated with visceral involvement. Generalized morphea is the most severe form of localized morphea. Clinical diagnostic criteria are applied for diagnosis: four or more lesions larger than $3 \mathrm{~cm}$ in diameter or involvement of two or more of the seven body areas (the head and neck, the right and left upper extremities, the anterior and posterior trunks) [45].

Linear scleroderma is characterized by one or more linear streaks of cutaneous induration that may involve the dermis, subcutaneous tissue, muscle, and underlying bone. It affects mainly children and is more common in females than males (3:1) and named "en coup de sabre" (LScs) when affecting the hemiface [46]. Parry-Romberg syndrome (PRS), also known as progressive hemifacial atrophy, clinically overlaps with LScs and can even affect the brain [47]. CT and MRI may show cerebral hemiatrophy or high signal of white

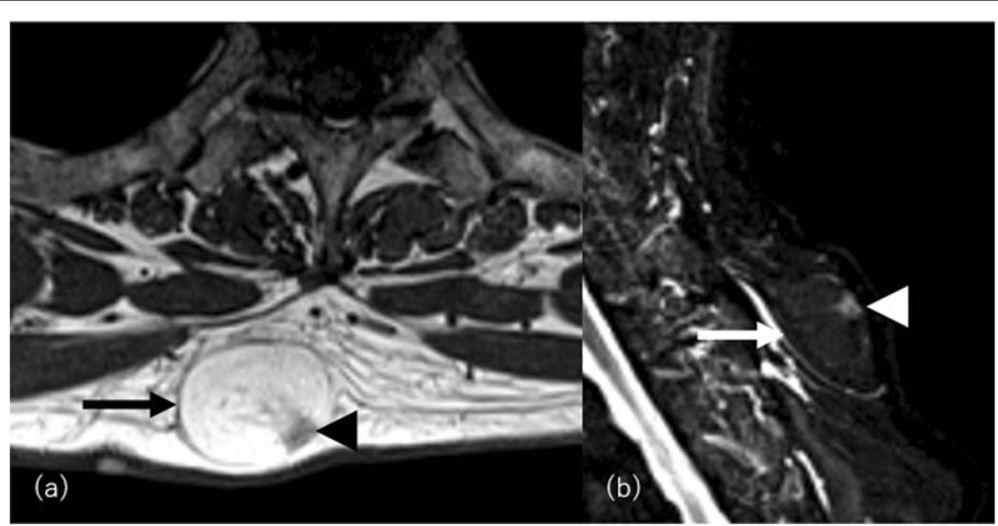

Fig. 18 Spindle cell lipoma in a 68-year-old man with a painless mass on the posterior neck. a Axial T1-weighted image and $\mathbf{b}$ sagittal STIR image show a subcutaneous, encapsulated fatty mass (arrows) with amorphous non-fatty signal area (arrowheads) representing intermingled components such as collagen fibers, myxoid matrix, and vascular elements 


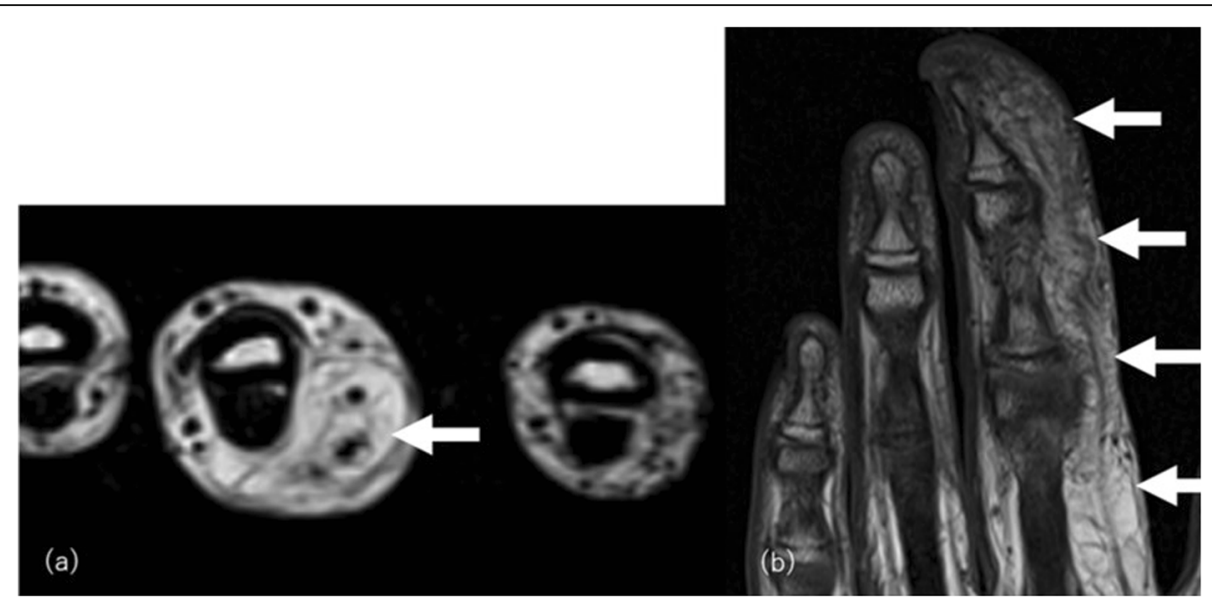

Fig. 19 Lipomatosis of the median nerve in an 11-year-old girl without symptoms. a Axial T2- and (b) coronal T1-weighted images reveal softtissue hypertrophy with predominance of fat in the radial side of the middle finger along with the neurovascular structure (arrows)

matter on T2-weighted image ipsilateral to the affected facial side not only atrophy of the skin and underlying bone and soft tissue (Fig. 11) [48].

LEP is an unusual variant of lupus erythematosus (LE), which occurs in $1-3 \%$ of patients with cutaneous LE [49]. LEP primarily involves subcutaneous tissues and tends to have a chronic course resulting in broad lipoatrophy. Face and limbs are most commonly involved [50].

\section{Stress/trauma-induced}

\section{Post-traumatic lipoatrophy/hypertrophy}

Posttraumatic subcutaneous lipoatrophy occurs following a fall, blunt injury (Fig. 12), or surgery (Fig. 13), with subsequent fat tissue damage, organized hemorrhage, fat necrosis, and fibrosis [51]. Often, the interval between the injury and initial observation of the deformity is prolonged. It is more prevalent in women and children, usually appearing on the shins, thighs, arms, breasts, and buttocks [52]. The radiologic appearance of subcutaneous posttraumatic lipoatrophy may accompany linear spiculated lesion with globular component on MRI, correlated with lipogranuloma pathologically $[53,54]$.

Although the pathogenesis of post-traumatic lipohypertrophy, so-called "pseudolipoma," is not well-proven, blunt trauma has classically been reported as the cause [55]. Repetitive mechanical stress also induces a prominent increase in the volume of subcutaneous adipose tissue. By carrying heavy loads, abnormal local fat accumulation on the shoulder has been reported in festival participants in Japan and Southern Italy, wine porters, brewery workers, and heavy handbag carriers [56].

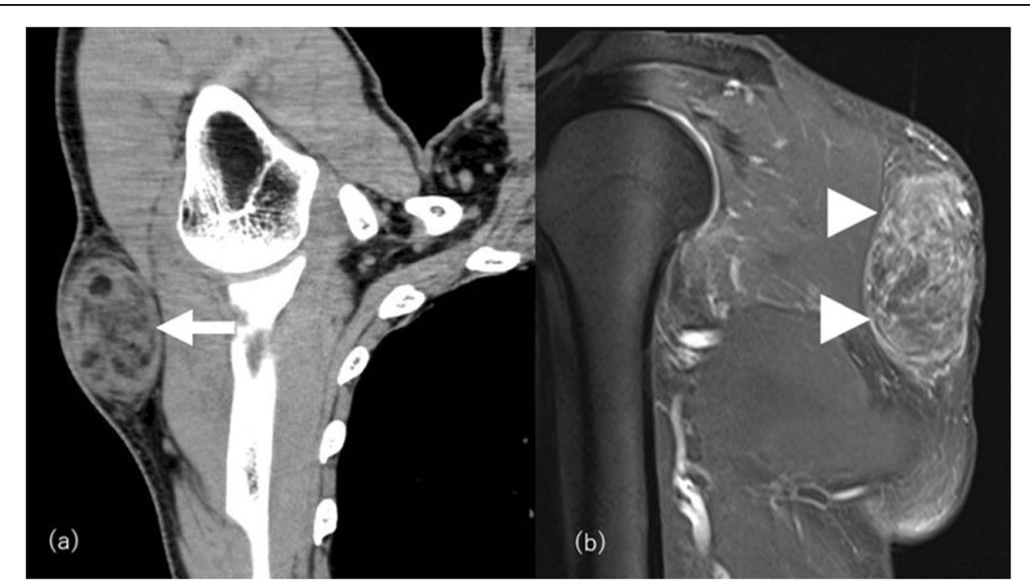

Fig. 20 Atypical lipomatous tumor in a 62-year-old male with a painless, firm, and mobile mass gradually increasing in the right back. a Coronal CT image shows a fat-containing inhomogeneous density mass (arrow). b On post-contrast fat-saturated T1-weighted image, the non-fatty lesion shows moderate enhancement (arrowheads). Surgically diagnosed as ALT with abundant fat necrosis 
On CT and MRI, an increase in the volume of noncapsulated adipose tissue is evident (Fig. 14).

\section{Semicircular lipoatrophy}

Semicircular lipoatrophy is a type of localized lipoatrophy characterized by band-like horizontal depressions measuring 2 to $4 \mathrm{~cm}$ in width, located on the anterolateral aspect of the thighs (Fig. 15). The most widely accepted cause is repetitive microtrauma against such as the edge of furniture or tight-fitting clothes [57]. Semicircular lipoatrophy is frequently reported among office working women aged 20 to 40 years. The lesion is typically observed at $72-73$ $\mathrm{cm}$ above the ground, which is the standard height of office furniture [58]. Other risk factors are reported to include overweight, routine electrical shock, clothing made of fibers, wearing of rubber-soled shoes, and low humidity air conditioning [58]. When the suspected cause is found and removed from the daily life, the lesions resolve within 9 months to 4 years [59]. MRI shows a clear superficial loss of subcutaneous tissue without findings of panniculitis and thickening of interlobular septa with a reduction in the size of fat lobules [60].

\section{Others}

\section{Familial partial lipodystrophies}

Familial partial lipodystrophy is inherited in an autosomal dominant or recessive fashion showing a mixture of partial fat atrophy and accumulation with onset during childhood or puberty [12]. The phenotypic heterogeneity of familial partial lipodystrophy has been reported as types 1-6.

\section{Mandibuloacral dysplasia}

Mandibuloacral dysplasia is an extremely rare autosomal recessive progeroid syndrome due to mutations in genes encoding nuclear lamina proteins, lamins A/C (LMNA) or prelamin A processing enzyme, and zinc metalloproteinase (ZMPSTE24) which has been reported in approximately 40 case reports [61, 62]. Lipoatrophy appears in childhood or early adolescence. In addition to lipodystrophy, this condition shows craniofacial and skeletal abnormalities including mandibular and clavicular hypoplasia, delayed closure of the cranial sutures, acro-osteolysis, joint contractures or bird-like facies with postnatal growth retardation, and cutaneous changes [12].

\section{Acquired partial lipodystrophy (Barraquer-Simons syndrome)} Approximately 250 cases of acquired partial lipodystrophy have been reported. It typically shows a childhood or adolescent onset with a unique, cephalocaudal progression of fat loss with fat accumulation in the lower half of the body [63]. Infections, autoimmune diseases, and membranoproliferative glomerulonephritis have been linked to the development of acquired partial lipodystrophy [12].

\section{Adipose tumors as differential diagnoses}

Adipocytic tumors are the most common soft tissue tumors clinically, and radiologists always need to differentiate them from those conditions showing localized abnormal fat distribution discussed above. Here, we illustrate imaging findings of benign and intermediate adipose tumors (lipoma, angiolipoma, spindle cell/pleomorphic lipoma, lipomatosis of nerve, and welldifferentiated liposarcoma/atypical lipomatous tumor) which can be major differential diagnoses.

Lipoma accounts for approximately $50 \%$ of all soft tissue tumors and the most common subcutaneous neoplasm consists mainly of mature adipose tissue [64]. Lipoma usually demonstrates an encapsulated high signal mass on T2and T1-weighted images that contain thin septa less than $2 \mathrm{~mm}$, with suppression on fat saturated images (Fig. 16), but some show a non-capsulated pattern. Lipoma commonly manifests as a solitary mass but can also manifest as multiple masses in 5-15\% of cases [64]. Those atypical lipomas can resemble non-neoplastic abnormal fat distribution conditions. Lipomas are usually asymptomatic, though local pain, tenderness, or nerve compression is reported when they become large [65]. Abnormal nonneoplastic fat distribution conditions usually show no such symptoms though mechanical obstruction or metabolic dysfunction may also be present. Fat necrosis within a lipoma presents a variable imaging appearance with inflammatory or fibrotic change, and these can be difficult to differentiate from fat accumulation due to mechanical pressure or trauma, other benign adipose tumors, or well-differentiated liposarcoma.

Angiolipoma is a benign neoplasm consisted of mature adipose tissue and vascular structures. It represents as well-defined multiple, small subcutaneous mass with tenderness located commonly in the forearm, upper arm, or trunk [66]. The MR imaging features of these lesions are the presence of fat nodules with or without low signal on T1- or T2-weighted images with or without high signal on fat saturated T2-weighted images representing the prominent vasculature [67] (Fig. 17). Lipogranulomas found with post-traumatic lipoatrophy/lipohypertrophy would be the differential diagnosis, though the presence of pain, absence of traumatic history, and normal distribution of surrounding subcutaneous fat demonstrate the different nature of those conditions.

Spindle cell/pleomorphic lipoma is a benign, wellcircumscribed subcutaneous mass commonly located in the posterior neck or shoulder in middle-aged men with frequent expression of androgen receptor [68]. Histologically, spindle cell/pleomorphic lipoma consists of adipocytes with varying proportions of spindle cells with 
rope-like collagen bundles [69]. Fat is reported to be detectable in $89 \%$ of these lesions, ranging from $25 \%$ to $75 \%$ of the tumor volume on MRI [70]. Non-adipose components are similar to those of skeletal muscle on T1-weighted imaging and hyperintense on fat-saturated fluid-sensitive sequences (Fig. 18) Intense enhancement of the non-adipose component further supports this diagnosis. The mass is generally firmer than lipomas or most conditions with non-neoplastic localized abnormal fat distribution. When it occurs in atypical locations, it becomes challenging to differentiate from liposarcomas or even other non-adipose soft tissue tumors.

Lipomatosis of a nerve is a rare, not fully understood benign condition, which has been referred to variously as fibrolipomatous hamartoma, perineural lipoma, fatty infiltration of the nerve, or neural fibrolipoma [64]. This condition most commonly occurs in patients before 30 years of age, involving the median nerve of the wrist and hand. Accompanying varying degrees of mesenchymal overgrowth including adipose tissue with frequent sensory symptoms such as paresthesia or numbness, with or without macrodactyly, is the typical presentation [71] (Fig. 19). The location and adipose tissue distribution interspersing nerve bundles are imaging findings distinctive from those of already discussed non-neoplastic abnormal fat distribution conditions.

Well-differentiated liposarcoma/atypical lipomatous tumor (ALT) is the most common liposarcoma, classified as an intermediate (locally aggressive) adipocytic tumor. It most commonly locates in a deep-seated well-vascularized area and rarely in subcutaneous locations [72]. Welldifferentiated liposarcoma and ALT are synonyms describing similar lesions morphologically and karyotypically and are differentiated by the location of the tumor and the surgical resectability [66]. The term of well-differentiated liposarcoma is used for lesions exclusively in the retroperitoneum, mediastinum, and spermatic cord, while ALT is used for lesions arising elsewhere [66]. Well-differentiated liposarcoma/ALT can be the differential diagnosis for multiple symmetric lipomatosis, hypercortisolism, or posttraumatic lipohypertrophy with fat necrosis. The imaging findings typically depict a fatty mass with thick and irregular septa, septal enhancement, and non-adipose areas with prominent mass effect, local encasement of vital organs, and asymmetrical distribution compared with those nonneoplastic conditions [73] (Fig. 20).

\section{Conclusion}

Radiologists should be aware of the typical imaging findings and disease spectrum of abnormal deposition of subcutaneous fat. Although the underlying conditions are diverse, the radiological findings can be the key making possible an early assessment and suggesting the optimal methods needed to achieve a definitive diagnosis.

\section{Abbreviations}

ACTH: Adrenocorticotropic hormone; AGL: Acquired generalized lipodystrophy; ALT: Atypical lipomatous tumor; BAT: Brown adipose tissue; CGL: Congenital generalized lipodystrophy; HAART: Highly active antiretroviral therapy; HALS: HIV-1/highly active antiretroviral therapyassociated lipodystrophy syndrome; HIV: Human immunodeficiency virus; LE: Lupus erythematosus; LEP: Lupus erythematosus profundus; LScS: Localized scleroderma en coup de sabre; MSL: Multiple symmetric lipomatosis; NRTIs: Thymidine analog nucleoside reverse transcriptase inhibitors; PRS: Parry-Romberg syndrome; SCAT: Subcutaneous fat tissue; VSA: Visceral fat tissue; WAT: White adipose tissue

\section{Acknowledgements}

The authors thank Dr. Won Bae (Associate Professor, Dept. of Radiology, University of California, San Diego) for his input on preparation of the manuscript and organization of the content. We are also grateful to Dr. Yuichi Ishikawa of Teikyo University School of Medicine and Mr. John Gelblum for the assistance during the drafting of the revised version of the manuscript.

\section{Authors' contributions}

AY contributed to the conception, drafting, and imaging data acquisition. YK contributed to the pathological data acquisition. TK contributed to imaging data acquisition. HT contributed to the conception and imaging data acquisition. SF contributed to the conception and drafting. KS contributed to imaging data acquisition. $\mathrm{HO}$ contributed to the conception of the study. All authors read and approved the final manuscript.

Funding

None

\section{Availability of data and materials}

The datasets used and/or analyzed during the current study are available from the corresponding author on reasonable request.

Ethics approval and consent to participate

This review was approved by the ethics committee in Teikyo University School of Medicine, Tokyo, Japan (TUIC-COI 18-1494).

\section{Consent for publication}

Informed consent for publication was taken on document independently.

\section{Competing interests}

The authors declare that they have no competing interests.

\section{Author details}

${ }^{1}$ Department of Radiology, Teikyo University School of Medicine, 2-11-1 Kaga Itabashi-ku, Tokyo 173-8606, Japan. ${ }^{2}$ Department of Pathology, Teikyo University School of Medicine, 2-11-1 Kaga Itabashi-ku, Tokyo 173-8606, Japan. ${ }^{3}$ Department of Endocrinology, Metabolism, and Hypertension Research, Clinical Research Institute, National Hospital Organization Kyoto Medical Center, 1-1 Fukakusa Mukaihata-cho, Fushimi-ku, Kyoto 612-8555, Japan. ${ }^{4}$ Department of Radiology, Chiba Cancer Center, 666-2 Nitonacho, Chuo-ku, Chiba-shi, Chiba 260-8717, Japan.

Received: 26 August 2019 Accepted: 17 December 2019

Published online: 13 February 2020

\section{References}

1. Gersh I, Still MA (1945) Blood vessels in fat tissue. Relation to problems of gas exchange. J Exp Med 81:219-232

2. Cinti S (2005) The adipose organ. Prostaglandins Leukot Essent Fat Acids 73: 9-15

3. Avram AS, Avram MM, James WD (2005) Subcutaneous fat in normal and diseased states: 2. Anatomy and physiology of white and brown adipose tissue. J Am Acad Dermatol 53:671-683

4. Napolitano $L$ (1963) The differentiation of white adipose cells. An electron microscope study. J Cell Biol 18:663-679

5. Lean ME (1989) Brown adipose tissue in humans. Proc Nutr Soc 48:243-256

6. Raboi CA, Smith W (1999) Brown fat necrosis in the setting of congenital heart disease and prostaglandin E1 use: a case report. Pediatr Radiol 29:61-63 
7. Okuyama C, Ushijima Y, Kubota T et al (2003) 1231Metaiodobenzylguanidine uptake in the nape of the neck of children: likely visualization of brown adipose tissue. J Nucl Med 44:1421-1425

8. Wajchenberg BL (2000) Subcutaneous and visceral adipose tissue: their relation to the metabolic syndrome. Endocr Rev 21:697-738

9. Smith SR, Lovejoy JC, Greenway F et al (2001) Contributions of total body fat, abdominal subcutaneous adipose tissue compartments, and visceral adipose tissue to the metabolic complications of obesity. Metabolism 50:425-435

10. Abate N, Garg A, Peshock RM, Stray-Gundersen J, Grundy SM (1995) Relationships of generalized and regional adiposity to insulin sensitivity in men. J Clin Invest 96:88-98

11. Frayn KN (2000) Visceral fat and insulin resistance--causative or correlative? Br J Nutr 83(Suppl 1):S71-S77

12. Garg A (2011) Clinical review\#: Lipodystrophies: genetic and acquired body fat disorders. J Clin Endocrinol Metab 96:3313-3325

13. Garg A (2000) Lipodystrophies. Am J Med 108:143-152

14. Chandalia M, Garg A, Vuitch F, Nizzi F (1995) Postmortem findings in congenital generalized lipodystrophy. J Clin Endocrinol Metab 80:3077-3081

15. Agarwal AK, Simha V, Oral EA et al (2003) Phenotypic and genetic heterogeneity in congenital generalized lipodystrophy. J Clin Endocrinol Metab 88:4840-4847

16. Billings JK, Milgraum SS, Gupta AK, Headington JT, Rasmussen JE (1987) Lipoatrophic panniculitis: a possible autoimmune inflammatory disease of fat. Report of three cases. Arch Dermatol 123:1662-1666

17. Ebadi M, Mazurak VC (2014) Evidence and mechanisms of fat depletion in cancer. Nutrients 6:5280-5297

18. Murphy RA, Wilke MS, Perrine M et al (2010) Loss of adipose tissue and plasma phospholipids: relationship to survival in advanced cancer patients. Clin Nutr 29:482-487

19. Agustsson T, Ryden M, Hoffstedt $J$ et al (2007) Mechanism of increased lipolysis in cancer cachexia. Cancer Res 67:5531-5537

20. Batista ML Jr, Henriques FS, Neves RX et al (2016) Cachexia-associated adipose tissue morphological rearrangement in gastrointestinal cancer patients. J Cachexia Sarcopenia Muscle 7:37-47.

21. Sullivan PF (1995) Mortality in anorexia nervosa. Am J Psychiatry 152:1073-1074

22. Gill CM, Torriani M, Murphy $R$ et al (2016) Fat attenuation at CT in anorexia nervosa. Radiology 279:151-157

23. Boutin RD, White LM, Laor T et al (2015) MRI findings of serous atrophy of bone marrow and associated complications. Eur Radiol 25:2771-2778

24. Legroux-Gerot I, Vignau J, D'Herbomez M et al (2007) Evaluation of bone loss and its mechanisms in anorexia nervosa. Calcif Tissue Int 81:174-182

25. Misra A, Garg A, Abate N, Peshock RM, Stray-Gundersen J, Grundy SM (1997) Relationship of anterior and posterior subcutaneous abdominal fat to insulin sensitivity in nondiabetic men. Obes Res 5:93-99

26. Carr A (2003) HIV lipodystrophy: risk factors, pathogenesis, diagnosis and management. AIDS 17(Suppl 1):S141-S148

27. Mateo MG, Gutierrez Mdel M, Vidal F, Domingo P (2014) An update on the pharmacological strategies in the treatment of HIV-1-associated adipose redistribution syndromes. Expert Opin Pharmacother 15:1749-1760

28. Guaraldi G, Fontdevila J, Christensen LH et al (2011) Surgical correction of HIV-associated facial lipoatrophy. AIDS 25:1-12

29. Jacobson DL, Knox T, Spiegelman D, Skinner S, Gorbach S, Wanke C (2005) Prevalence of, evolution of, and risk factors for fat atrophy and fat deposition in a cohort of HIV-infected men and women. Clin Infect Dis 40:1837-1845

30. Rochira V, Zirilli L, Diazzi C, Romano S, Carani C (2012) Clinical and radiological evidence of the recurrence of reversible pegvisomant-related lipohypertrophy at the new site of injection in two women with acromegaly: a case series. J Med Case Rep 6:2

31. Radermecker RP, Pierard GE, Scheen AJ (2007) Lipodystrophy reactions to insulin: effects of continuous insulin infusion and new insulin analogs. Am J Clin Dermatol 8:21-28

32. Hauner H, Stockamp B, Haastert B (1996) Prevalence of lipohypertrophy in insulin-treated diabetic patients and predisposing factors. Exp Clin Endocrinol Diabetes 104:106-110

33. Watson D, Vines R (1973) Variations in the incidence of lipodystrophy using different insulins. Med J Aust 1:248-250

34. Hadjiev B, Stefanova P, Shipkov C, Uchikov A, Mojallal A (2010) Madelung disease: on the morphologic criteria for diagnosis and treatment. Ann Plast Surg 64:807-808

35. Smith PD, Stadelmann WK, Wassermann RJ, Kearney RE (1998) Benign symmetric lipomatosis (Madelung's disease). Ann Plast Surg 41:671-673
36. Landis MS, Etemad-Rezai R, Shetty K, Goldszmidt M (2009) Case 143 Madelung disease. Radiology 250:951-954

37. Plummer C, Spring PJ, Marotta R et al (2013) Multiple symmetrical lipomatosisa mitochondrial disorder of brown fat. Mitochondrion 13:269-276

38. Mevio E, Sbrocca M, Mullace M, Viglione S, Mevio N (2012) Multiple symmetric lipomatosis: a review of 3 cases. Case Rep Otolaryngol 2012:910526

39. Wajchenberg BL, Bosco A, Marone MM et al (1995) Estimation of body fat and lean tissue distribution by dual energy $X$-ray absorptiometry and abdominal body fat evaluation by computed tomography in Cushing's disease. J Clin Endocrinol Metab 80:2791-2794

40. Dagenais GR, Yi Q, Mann JF, Bosch J, Pogue J, Yusuf S (2005) Prognostic impact of body weight and abdominal obesity in women and men with cardiovascular disease. Am Heart J 149:54-60

41. Allison DB, Fontaine KR, Manson JE, Stevens J, Vanltallie TB (1999) Annual deaths attributable to obesity in the United States. JAMA 282:1530-1538

42. Koch CA, Doppman JL, Watson JC, Patronas NJ, Nieman LK (1999) Spinal epidural lipomatosis in a patient with the ectopic corticotropin syndrome. N Engl J Med 341:1399-1400

43. Adler RA, Rosen CJ (1994) Glucocorticoids and osteoporosis. Endocrinol Metab Clin N Am 23:641-654

44. Winkelmann RK (1983) Panniculitis in connective tissue disease. Arch Dermatol 119:336-344

45. Fett N, Werth VP (2011) Update on morphea: part I. Epidemiology, clinical presentation, and pathogenesis. J Am Acad Dermatol 64:217-228 quiz 229-230

46. Careta MF, Romiti R (2015) Localized scleroderma: clinical spectrum and therapeutic update. An Bras Dermatol 90:62-73

47. Pinheiro TP, Silva CC, Silveira CS, Botelho PC, Pinheiro M, Pinheiro Jde J (2006) Progressive hemifacial atrophy--case report. Med Oral Patol Oral Cir Bucal 11:E112-E114

48. Longo D, Paonessa A, Specchio N et al (2011) Parry-Romberg syndrome and Rasmussen encephalitis: possible association. Clinical and neuroimaging features. J Neuroimaging 21:188-193

49. Requena L, Sanchez Yus E (2001) Panniculitis. Part II. Mostly lobular panniculitis. J Am Acad Dermatol 45:325-361 quiz 362-324

50. Park HS, Choi JW, Kim BK, Cho KH (2010) Lupus erythematosus panniculitis: clinicopathological, immunophenotypic, and molecular studies. Am J Dermatopathol 32:24-30

51. Crawford EA, King JJ, Fox EJ, Ogilvie CM (2009) Symptomatic fat necrosis and lipoatrophy of the posterior pelvis following trauma. Orthopedics 32:444

52. Tillman C, Holst R, Svedman C (2003) Traumatic fat necrosis: a case report. Acta Derm Venereol 83:227-228

53. Lopez JA, Saez F, Alejandro Larena J, Capelastegui A, Martin JI, Canteli B (1997) MRI diagnosis and follow-up of subcutaneous fat necrosis. J Magn Reson Imaging 7:929-932

54. Canteli B, Saez F, de los Rios A, Alvarez C (1996) Fat necrosis. Skeletal Radiol 25:305-307

55. Theumann N, Abdelmoumene A, Wintermark M, Schnyder P, Gailloud MC, Resnick D (2005) Posttraumatic pseudolipoma: MRI appearances. Eur Radiol 15:1876-1880

56. Aust MC, Spies M, Kall S et al (2007) Lipomas after blunt soft tissue trauma: are they real? Analysis of 31 cases. Br J Dermatol 157:92-99

57. Pomares Roche JM, Arrizabalaga Clemente P (2008) Lipoatrophy semicircularis. Med Clin (Barc) 130:213-215

58. Reinoso-Barbero L, Gonzalez-Gomez MF, Belanger-Quintana D et al (2013) Case-control study of semicircular lipoatrophy, a new occupational disease in office workers. J Occup Health 55:149-157

59. Nagore E, Sanchez-Motilla JM, Rodriguez-Serna M, Vilata JJ, Aliaga A (1998) Lipoatrophia semicircularis--a traumatic panniculitis: report of seven cases and review of the literature. J Am Acad Dermatol 39:879-881

60. Ogino J, Saga K, Tamagawa M, Akutsu Y (2004) Magnetic resonance imaging of semicircular lipoatrophy. Dermatology 209:340-341

61. Simha V, Agarwal AK, Oral EA, Fryns JP, Garg A (2003) Genetic and phenotypic heterogeneity in patients with mandibuloacral dysplasiaassociated lipodystrophy. J Clin Endocrinol Metab 88:2821-2824

62. Agarwal AK, Kazachkova I, Ten S, Garg A (2008) Severe mandibuloacral dysplasiaassociated lipodystrophy and progeria in a young girl with a novel homozygous Arg527Cys LMNA mutation. J Clin Endocrinol Metab 93:4617-4623

63. Fiorenza CG, Chou SH, Mantzoros CS (2011) Lipodystrophy: pathophysiology and advances in treatment. Nat Rev Endocrinol 7:137-150 
64. Murphey MD, Carroll JF, Flemming DJ, Pope TL, Gannon FH, Kransdorf MJ (2004) From the archives of the AFIP: benign musculoskeletal lipomatous lesions. Radiographics 24:1433-1466

65. Elia S, Cerioli A, Fiaschetti V, Granai AV (2015) Infraclavicular subpectoral lipoma causing thoracic outlet syndrome. Int I Surg Case Rep 9:101-104

66. Fletcher CDM, Bridge JA, Hogendoorn P, Mertens F (2013) WHO classification of tumours of soft tissue and bone, 4th edn. IARC Press, Lyon, France

67. Kitagawa Y, Miyamoto M, Konno S et al (2014) Subcutaneous angiolipoma: magnetic resonance imaging features with histological correlation. J Nippon Med Sch 81:313-319

68. Khashper A, Zheng J, Nahal A, Discepola F (2014) Imaging characteristics of spindle cell lipoma and its variants. Skeletal Radiol 43:591-597

69. Billings SD, Folpe AL (2007) Diagnostically challenging spindle cell lipomas: a report of 34 "low-fat" and "fat-free" variants. Am J Dermatopathol 29:437-442

70. Bancroft LW, Kransdorf MJ, Peterson JJ, Sundaram M, Murphey MD, O'Connor MI (2003) Imaging characteristics of spindle cell lipoma. AJR Am J Roentgenol 181:1251-1254

71. Tahiri Y, Xu L, Kanevsky J, Luc M (2013) Lipofibromatous hamartoma of the median nerve: a comprehensive review and systematic approach to evaluation, diagnosis, and treatment. J Hand Surg Am 38:2055-2067

72. Myhre-Jensen O (1981) A consecutive 7-year series of 1331 benign soft tissue tumours. Clinicopathologic data. Comparison with sarcomas. Acta Orthop Scand 52:287-293

73. El Ouni F, Jemni H, Trabelsi A et al (2010) Liposarcoma of the extremities: MR imaging features and their correlation with pathologic data. Orthop Traumatol Surg Res 96:876-883

\section{Publisher's Note}

Springer Nature remains neutral with regard to jurisdictional claims in published maps and institutional affiliations.

\section{Submit your manuscript to a SpringerOpen ${ }^{\circ}$ journal and benefit from:}

- Convenient online submission

- Rigorous peer review

- Open access: articles freely available online

- High visibility within the field

- Retaining the copyright to your article

Submit your next manuscript at $\boldsymbol{\nabla}$ springeropen.com 